\title{
Megastigmane Glucosides from Equisetum debile and E. diffusum
}

\author{
Tripetch Kanchanapoom, ${ }^{*, a}$ Hideaki Otsuka, ${ }^{b}$ and Somsak RuchiRaWaT ${ }^{c}$ \\ ${ }^{a}$ Department of Pharmaceutical Botany and Pharmacognosy, Faculty of Pharmaceutical Sciences, Khon Kaen University; \\ Khon Kaen 40002, Thailand: ${ }^{b}$ Department of Pharmacognosy, Graduate School of Biomedical Sciences, Hiroshima \\ University; Hiroshima 734-8553, Japan: and ${ }^{c}$ Chulabhorn Research Institute; Vipavadee Rangsit Highway, Bangkok \\ 10210, Thailand. Received April 4, 2007; accepted May 9, 2007
}

\begin{abstract}
A new megastigmane diglucoside, $(3 S, 5 R, 6 S, 7 E, 9 S)$-megastigman-7-ene-5,6-epoxy-3,9-diol 3,9- $O$ - $\beta$-D-diglucopyranoside (3), was isolated from the aerial portion of Equisetum debile along with macarangioside D (debiloside A), sammangaoside $A,(6 R, 9 S)$-3-oxo- $\alpha$-ionol 9- $O$ - $\beta$-D-glucopyranoside, debiloside $B$, kaempferol 3- $O$ sophoroside, kaempferol 3,7-O- $\beta$-D-diglucopyranoside, kaempferol 3-O-sophoroside-7-O- $\beta$-D-glucopyranoside, phenylethyl $O$ - $\beta$-D-glucopyranoside, $(Z)$-3-hexenyl $O$ - $\beta$-D-glucopyranoside, $(7 S, 8 R$-dehydrodiconiferyl $4-O$ - $\beta$ D-glucopyranoside, and L-tryptophan. The absolute configuration at C-6 of the original structure of debiloside $A$ was revised to $6 R$-configuration, and was identical with macarangioside $D(1)$. From the aerial portion of $E$. diffusum, four compounds, sammangaoside A, kaempferol 3-O-sophoroside and L-tryptophan and $(3 S, 5 R, 6 S, 7 E, 9 S)$-megastigman-7-ene-5,6-epoxy-3,9-diol 3- $O$ - $\beta$-D-glucopyranoside were identified. The spectroscopic data of $(3 S, 5 R, 6 S, 7 E, 9 S)$-megastigman-7-ene-5,6-epoxy-3,9-diol 3- $O$ - $\beta$-D-glucopyranoside (13) were found to be identical with corchoionoside A ( $9 R$-isomeric compound). The structure of corchoionoside $A$ was also discussed. Structure determinations were based on physical data and spectroscopic evidence.
\end{abstract}

Key words Equisetum debile; Equisetum diffusum; Equisetaceae; megastigmane glucoside; sammangaoside A

The species of family Equisetaceae are plants of a single living genus, including about 15 species, widely distributed in the temperate regions. Only two species, Equisetum debile RoxB. and E. diffusum D. Don, have been recorded in Thailand. They are used in Thai traditional medicine for diuretic purposes. Members of this family are known to contain several types of compounds such as flavonoids, steroids, megastigmanes and fatty acids. ${ }^{1-6)}$ In previous studies, flavonoids and megastigmanes were reported from dried whole part of $E$. debile collected from China., ${ }^{5,6)}$ However, phytochemical investigation of $E$. diffusum has not been carried out. This present paper describes the isolation and structure elucidation of chemical constituents from the aerial parts of both species, including megastigmane glucosides $(\mathbf{1}-\mathbf{5}$, 13), flavonoid glycosides (6-8), a phenylethanoid glucoside (9), an aliphatic glucoside (10), a neolignan glucoside (11), and an amino acid (12).

\section{Results and Discussion}

The methanolic extract of the aerial part of $E$. debile was suspended in $\mathrm{H}_{2} \mathrm{O}$ and extracted with $\mathrm{Et}_{2} \mathrm{O}$. The aqueous<smiles>[R]CC1=CC(=O)CC(C)(C)[C@H]1/C=C/C(C)O[R]([H])([H])O</smiles>

$1: \mathbf{R}=\mathbf{O H}$

$4: \mathbf{R}=\mathbf{H}$<smiles>CC(=O)OC(C)/C=C/C1=C(C)[C@H](O)[C@@H](O)CC1(C)C</smiles>

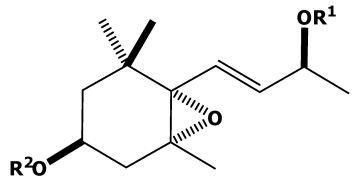

$2: R^{1}=\beta-D-G I C ; R^{2}=H$

$3: R^{1}=\beta-D-G I C ; R^{2}=\beta-D-G I C$

$13: R^{1}=H ; R^{2}=\beta-D-G I C$

$2 a=3 a=13 a: R^{1}=R^{2}=H$ layer was applied to a column of Diaion HP-20, with $\mathrm{H}_{2} \mathrm{O}$, $\mathrm{MeOH}$ and $\mathrm{Me}_{2} \mathrm{CO}$ as eluants, successively. The portion eluted with $\mathrm{MeOH}$ was separated by a combination of chromatographic procedures to provide 12 compounds.

The ${ }^{1} \mathrm{H}$ - and ${ }^{13} \mathrm{C}$-NMR spectroscopic and physical data of compound 1 were identical with those of a megastigmane glucoside, macarangioside $\mathrm{D}$, which was isolated from Macaranga tanarius. ${ }^{7}$ The spectroscopic and physical data of this compound were also coincident with those of debiloside A, previously reported from E. debile. ${ }^{6)}$ However, the absolute configuration at C-6 in the original structure of debiloside A (6S-configuration) was shown to be incorrect since the reported CD spectral data showed extreme values for $\Delta \varepsilon(\mathrm{nm})+83.0$ (247) and -5.9 (320), which correlated to the data of $6 R$-configurated compounds. ${ }^{8,9)}$ This evidence indicated that debiloside $A$ has a $6 R$-configuration instead of a $6 S$-configuration. Thus, this compound has two trivial names, and the name macarangioside $\mathrm{D}$ should be retained because its correct structure was elucidated first.

Compounds 2, 4 and $\mathbf{5}$ were also assigned as known megastigmane glucosides; sammangaoside $\mathrm{A},{ }^{10)}(6 R, 9 S)-3$ oxo- $\alpha$-ionol $9-O-\beta$-D-glucopyranoside ${ }^{8)}$ and debiloside $\mathrm{B}{ }^{6}$ ) respectively.

Compound 3 was isolated as an amorphous powder and its molecular formula was determined to be $\mathrm{C}_{25} \mathrm{H}_{42} \mathrm{O}_{13}$ by high resolution atmospheric pressure chemical ionization (HRAPCI) mass spectrometric analysis. The ${ }^{13} \mathrm{C}-\mathrm{NMR}$ spectroscopic data showed the presence of two terminal $\beta$-D-glucopyranosyl units together with the remaining 13 carbon signals for the aglycone moiety, which was expected to have a megastigmane skeleton. The chemical shifts of this compound were closely related to those of sammangoside A (2) ${ }^{10)}$ except for a set of additional signals arising from one terminal $\beta$-D-glucopyranosyl unit. This additional unit was assigned to locate at $\mathrm{C}-3$ of the aglycone part due to the downfield shift of this carbon atom $+8.3 \mathrm{ppm}$ together with the upfield shifts of $\mathrm{C}-2(-2.4 \mathrm{ppm})$ and $\mathrm{C}-4(-3.2 \mathrm{ppm})$ in 
Table 1. $\quad{ }^{1}$ H-NMR Spectroscopic Data of Compounds $\mathbf{3}$ and $\mathbf{1 3}$

\begin{tabular}{|c|c|c|}
\hline No. & 3 & 13 \\
\hline \multirow[t]{2}{*}{2} & $1.35(1 \mathrm{H}, \mathrm{dd}, J=13.8,10.6 \mathrm{~Hz})$ & $1.34(1 \mathrm{H}, \mathrm{dd}, J=13.0,10.4 \mathrm{~Hz})$ \\
\hline & $1.71(1 \mathrm{H}$, br dd, $J=13.8,3.5 \mathrm{~Hz})$ & $1.70(1 \mathrm{H}, \mathrm{ddd}, J=13.0,3.5,1.8 \mathrm{~Hz})$ \\
\hline 3 & $3.85(1 \mathrm{H}, \mathrm{m})$ & $3.87(1 \mathrm{H}, \mathrm{m})$ \\
\hline \multirow[t]{2}{*}{4} & $1.76(1 \mathrm{H}, \mathrm{dd}, J=14.3,8.4 \mathrm{~Hz})$ & $1.74(1 \mathrm{H}, \mathrm{dd}, J=14.3,8.6 \mathrm{~Hz})$ \\
\hline & $2.38(1 \mathrm{H}, \mathrm{dd}, J=14.3,5.3 \mathrm{~Hz})$ & $2.38(1 \mathrm{H}, \mathrm{ddd}, J=14.3,5.8,1.0 \mathrm{~Hz})$ \\
\hline 7 & $6.05(1 \mathrm{H}, \mathrm{d}, J=15.6 \mathrm{~Hz})$ & $5.90(1 \mathrm{H}, \mathrm{dd}, J=15.6,1.5 \mathrm{~Hz})$ \\
\hline 8 & $5.57(1 \mathrm{H}, \mathrm{dd}, J=15.6,8.5 \mathrm{~Hz})$ & $5.66(1 \mathrm{H}, \mathrm{dd}, J=15.6,5.7 \mathrm{~Hz})$ \\
\hline 9 & $4.52(1 \mathrm{H}, \mathrm{dq}, J=8.5,5.9 \mathrm{~Hz})$ & $4.29(1 \mathrm{H}, \mathrm{dq}, J=5.7,5.5 \mathrm{~Hz})$ \\
\hline 10 & $1.30(3 \mathrm{H}, \mathrm{d}, J=5.9 \mathrm{~Hz})$ & $1.22(1 \mathrm{H}, \mathrm{d}, J=5.5 \mathrm{~Hz})$ \\
\hline 11 & $0.94(3 \mathrm{H}, \mathrm{s})$ & $0.94(3 \mathrm{H}, \mathrm{s})$ \\
\hline 12 & $1.13(3 \mathrm{H}, \mathrm{s})$ & $1.12(3 \mathrm{H}, \mathrm{s})$ \\
\hline 13 & $1.25(3 \mathrm{H}, \mathrm{s})$ & $1.21(3 \mathrm{H}, \mathrm{s})$ \\
\hline \multicolumn{3}{|l|}{ Glc } \\
\hline $1^{\prime}$ & $4.27(1 \mathrm{H}, \mathrm{d}, J=7.8 \mathrm{~Hz})$ & \\
\hline $2^{\prime}$ & $3.18(1 \mathrm{H}, \mathrm{dd}, J=8.8,7.8 \mathrm{~Hz})$ & \\
\hline $3^{\prime}$ & $3.26(1 \mathrm{H})^{a)}$ & \\
\hline $4^{\prime}$ & $3.26(1 \mathrm{H})^{a}$ & \\
\hline $5^{\prime}$ & $3.33(1 \mathrm{H}, \mathrm{m})$ & \\
\hline \multirow[t]{2}{*}{$6^{\prime}$} & $3.62(1 \mathrm{H}, \mathrm{dd}, J=11.9,6.0 \mathrm{~Hz})$ & \\
\hline & $3.85(1 \mathrm{H}, \mathrm{dd}, J=11.9,2.0 \mathrm{~Hz})$ & \\
\hline \multicolumn{3}{|l|}{ Glc } \\
\hline $1^{\prime \prime}$ & $4.33(1 \mathrm{H}, \mathrm{d}, J=7.7 \mathrm{~Hz})$ & $4.33(1 \mathrm{H}, \mathrm{d}, J=7.8 \mathrm{~Hz})$ \\
\hline $2^{\prime \prime}$ & $3.11(1 \mathrm{H}, \mathrm{dd}, J=8.8,7.7 \mathrm{~Hz})$ & $3.11(1 \mathrm{H}, \mathrm{dd}, J=8.9,7.8 \mathrm{~Hz})$ \\
\hline $3^{\prime \prime}$ & $3.26(1 \mathrm{H})^{a)}$ & $3.24(1 \mathrm{H})^{a)}$ \\
\hline $4^{\prime \prime}$ & $3.26(1 \mathrm{H})^{a)}$ & $3.24(1 \mathrm{H})^{a)}$ \\
\hline $5^{\prime \prime}$ & $3.33(1 \mathrm{H}, \mathrm{m})$ & $3.33(1 \mathrm{H}, \mathrm{m})$ \\
\hline \multirow[t]{2}{*}{$6^{\prime \prime}$} & $3.65(1 \mathrm{H}, \mathrm{dd}, J=11.9,5.0 \mathrm{~Hz})$ & $3.66(1 \mathrm{H}, \mathrm{dd}, J=11.9,5.1 \mathrm{~Hz})$ \\
\hline & $3.83(1 \mathrm{H}, \mathrm{dd}, J=11.9,2.0 \mathrm{~Hz})$ & $3.83(1 \mathrm{H}, \mathrm{dd}, J=11.9,2.0 \mathrm{~Hz})$ \\
\hline
\end{tabular}

a) Chemical shifts were obtained approximately by HSQC.

comparison with compound $\mathbf{2}$. In order to confirm the stereochemistry of the sugar unit and the absolute configurations at C-3 and C-9 of the aglycone moiety, compounds 2 and $\mathbf{3}$ were hydrolyzed with crude hesperidinase to provide aglycones $\mathbf{2 a}$ and $\mathbf{3 a}$, in addition to two sugar fractions from aqueous layers. The stereochemistry of glucose of both compounds was determined to be $\mathrm{D}$-form by treating the residue of two sugar fractions with L-cysteine methyl ester to provide the thiazolidine derivatives of sugars, and comparison of the $R f$ values with the standard samples of thiazolidine derivatives of D-glucose (see Experimental). Two aglycones were expected to present the same structure, and could be identical to each other as $(3 S, 5 R, 6 S, 7 E, 9 S)$-megastigman-7-ene-5,6epoxy-3,9-diol by NMR spectral analysis, and the results from optical rotation values $\left(\mathbf{2 a},[\alpha]_{\mathrm{D}}^{29}-88.0^{\circ}\right.$ and $\mathbf{3 a},[\alpha]_{\mathrm{D}}^{29}$ $\left.-87.9^{\circ}\right) .{ }^{11)}$ The absolute configurations at $\mathrm{C}-3$ and $\mathrm{C}-9$ were confirmed to be $3 S$ and $9 S$, respectively, by the application of $\beta$-D-glucosylation shift effects on carbon chemical shifts of secondary hydroxyl groups and the upfield shift differences of their neighboring carbon atoms in the aglycone part (see Table 2). ${ }^{12)}$ Moreover, the appearance of the chemical shift of C-9 at $74.8 \mathrm{ppm}$ is indicative of a $9 S$-configuration. ${ }^{8,13)}$ Therefore, compound 3 was assigned as $(3 S, 5 R, 6 S, 7 E, 9 S)$ megastigman-7-ene-5,6-epoxy-3,9-diol 3,9-O- $\beta$-D-diglucopyranoside.

The remaining isolated compounds from $E$. debile were identified as kaempferol 3-O-sophoroside (6), kaempferol 3,7-O- $\beta$-D-diglucopyranoside (7), kaempferol 3-O-sophoroside-7-O- $\beta$-D-glucopyranoside (8), phenyethyl $O$ - $\beta$-D-glucopyranoside (9), (Z)-3-hexenyl $O$ - $\beta$-D-glucopyranoside (10), $(7 S, 8 R)$-dehydrodiconiferyl $4-O-\beta$-D-glucopyranoside (11), and L-tryptophan (12) by physical data and from spectro-
Table 2. ${ }^{13} \mathrm{C}$-NMR Spectroscopic Data of Compounds $\mathbf{3}$ and $\mathbf{1 3}$

\begin{tabular}{|c|c|c|}
\hline No. & 3 & 13 \\
\hline 1 & 35.8 & 35.9 \\
\hline 2 & $45.5(-2.5)^{a)}$ & 45.7 \\
\hline 3 & $72.9(+8.3)$ & 73.0 \\
\hline 4 & $38.4(-3.2)$ & 38.5 \\
\hline 5 & 67.7 & 67.8 \\
\hline 6 & 71.3 & 71.3 \\
\hline 7 & 129.5 & 125.7 \\
\hline 8 & $136.0(-3.1)^{a)}$ & 139.1 \\
\hline 9 & $74.8(+6.1)$ & 68.7 \\
\hline 10 & $22.5(-1.4)$ & 23.9 \\
\hline 11 & 25.3 & 25.2 \\
\hline 12 & 29.9 & 29.8 \\
\hline 13 & 20.8 & 20.3 \\
\hline \multicolumn{3}{|c|}{ Glc-9S } \\
\hline $1^{\prime}$ & 101.3 & \\
\hline $2^{\prime}$ & 75.0 & \\
\hline $3^{\prime}$ & 78.3 & \\
\hline $4^{\prime}$ & 71.8 & \\
\hline $5^{\prime}$ & 78.1 & \\
\hline $6^{\prime}$ & 62.9 & \\
\hline \multicolumn{3}{|c|}{ Glc- $3 S$} \\
\hline $1^{\prime \prime}$ & 102.9 & 102.9 \\
\hline $2^{\prime \prime}$ & 75.2 & 75.2 \\
\hline $3^{\prime \prime}$ & 78.2 & 78.2 \\
\hline $4^{\prime \prime}$ & 71.6 & 71.7 \\
\hline $5^{\prime \prime}$ & 77.8 & 77.9 \\
\hline $6^{\prime \prime}$ & 62.7 & 62.7 \\
\hline
\end{tabular}

a) $\Delta \delta_{3-2 a}$

scopic evidence. ${ }^{2,3,10,14,15)}$

From the methanolic extract of the second species, E. diffusum, four compounds were isolated. Three were elucidated to be the same compounds as reported from E. debile; sammangaoside A (2), kaempferol 3-O-sophoroside (6) and Ltryptophan (12).

Compound 13 was obtained as an amorphous powder, and its elemental composition was determined to be $\mathrm{C}_{10} \mathrm{H}_{32} \mathrm{O}_{8}$ by HR-APCI mass spectrometric analysis. Inspection of the ${ }^{13} \mathrm{C}$ NMR spectroscopic data revealed the presence of 13 carbon signals of the aglycone moiety together with six carbon signals of a $\beta$-D-glucopyranosyl unit, corresponding to a megastigmane glucoside. The chemical shifts of this compound were closely related to those of compounds $\mathbf{2}, \mathbf{3}$ and 2a. In particular, the chemical shifts of the ring system were in agreement with those of $\mathbf{3}$, and those of the side chain were compatible to those of $\mathbf{2 a}$, suggesting that this compound prosessed the same aglycone moiety due to the co-occurrence of the same aglycone in the same species or genus, and the sugar part was connected to C-3. Enzymatic hydrolysis of 13 with crude herperidinase afforded 13a together with a sugar fraction from the aqueous layer. The stereochemistry of glucose was assigned to be D-form by the method described above. The chemical shifts and the optical rotation value $\left([\alpha]_{\mathrm{D}}^{29}-88.3^{\circ}\right)$ of 13a were fully consistent with those of $(3 S, 5 R, 6 S, 7 E, 9 S)$-megastigman-7-ene-5,6-epoxy-3,9-diol (2a or 3a). Consequently, the structure of compound $\mathbf{1 3}$ was assigned as $(3 S, 5 R, 6 S, 7 E, 9 S)$-megastigman-7-ene-5,6-epoxy3,9-diol 3-O- $\beta$-D-glucopyranoside. In fact, the structure of this compound was firstly reported with the trivial name corchoionoside A, which showed a $9 S$-configuration. ${ }^{16)}$ However, the structure of corchoionoside A was revised to have a 
$9 R$-configuration, ${ }^{17)}$ which was identical with the structure of stratioside I. ${ }^{18)}$ It should be noted that compound 13 might not have been isolated for the first time since two isomeric compounds, $9 S$ and $9 R$-configurations, provided the identical NMR spectroscopic data. Also, previous studies have reported the isolation of corchoionoside $\mathrm{A}$, which indicated the presence of a $9 S$-configuration in the structure. ${ }^{19-22)}$

\section{Experimental}

General Procedures NMR spectra were recorded in $\mathrm{CD}_{3} \mathrm{OD}$ using a JEOL JNM $\alpha-400$ spectrometer $\left(400 \mathrm{MHz}\right.$ for ${ }^{1} \mathrm{H}-\mathrm{NMR}$ and $100 \mathrm{MHz}$ for ${ }^{13} \mathrm{C}-\mathrm{NMR}$ ). MS values were obtained on a Bruker Micro TOF-LC mass spectrometer. Optical rotations were measured with a JASCO P-1020 polarimeter. CD spectrum was recorded on a Jasco J-810 spectropolarimeter. For column chromatography, silica gel 60 (70-230 mesh, no. 7734, Merck), RP-18 (50 $\mu \mathrm{m}, \mathrm{YMC}$ ), and Diaion HP-20 (Mitsubishi Chemical Industries Co., Ltd.) were used. Preparative HPLC was carried out on an ODS column $(250 \times 20 \mathrm{~mm}$ i.d., Nacalai Tesque, Inc.) with a JASCO RI-2031 refractive index detector. The flow rate was $6 \mathrm{ml} / \mathrm{min}$. The solvent systems were: I) EtOAc- $\mathrm{MeOH}(9: 1)$; II) EtOAc- $\mathrm{MeOH}-\mathrm{H}_{2} \mathrm{O}$ (40:10:1); III) EtOAc$\mathrm{MeOH}-\mathrm{H}_{2} \mathrm{O}(70: 30: 3)$; IV) EtOAc- $\mathrm{MeOH}-\mathrm{H}_{2} \mathrm{O}(6: 4: 1)$; V) $10-80 \%$ aqueous $\mathrm{MeOH}$; VI) $10 \%$ aqueous $\mathrm{MeCN}$; VII) $15 \%$ aqueous $\mathrm{MeCN}$; and VIII) $20 \%$ aqueous $\mathrm{MeCN}$. The spraying reagent used for TLC was $10 \%$ $\mathrm{H}_{2} \mathrm{SO}_{4}$ in $50 \%$ EtOH.

Plant Material Equisetum debile RoXB. ex VAUCHER was collected in July 2006 from Nam-Nao National Park, Phetchabun Province, Thailand. The latter species, E. diffusum D. Don was also collected in July 2006 from Doi-Phu-Kha National Park, Nan Province, Thailand. The plants were identified by Mr. Bamrung Thavinchiua, Department of Pharmaceutical Botany and Pharmacognosy, Faculty of Pharmaceutical Sciences, Khon Kaen University. Two voucher specimens (TK-PSKKU 0036 and TK-PSKKU 0037) are deposited in the Herbarium of the Faculty of Pharmaceutical Sciences, Khon Kaen University.

Extraction and Isolation Dried aerial part of E. debile $(1.3 \mathrm{~kg})$ was extracted with $\mathrm{MeOH}$. The solvent was concentrated in vacuo to give a greenish powder $(132.5 \mathrm{~g})$. This residue was suspended in $\mathrm{H}_{2} \mathrm{O}$ and defatted with $\mathrm{Et}_{2} \mathrm{O}$ three times (1.01 each). The aqueous layer was applied to a Diaion HP20 column and eluted with $\mathrm{H}_{2} \mathrm{O}, \mathrm{MeOH}$, and $\mathrm{Me}_{2} \mathrm{CO}$, successively. The fraction eluted with $\mathrm{MeOH}(9.6 \mathrm{~g})$ was concentrated to dryness and subjected to a silica gel column using solvent systems I (3.01), II (5.01), III (6.01), and IV (3.01). Nine fractions were collected. Fraction $2(1.0 \mathrm{~g})$ was applied to a column of RP-18 using solvent system V to give 10 fractions. Fractions 2-5 and 2-6 were combined and purified by preparative HPLC-ODS with solvent system VII to afford debiloside A (1, 12.6 $\mathrm{mg})$, sammangaoside A (2, $73.8 \mathrm{mg}$ ), phenylethyl $O-\beta$-D-glucopyranoside $(\mathbf{9}, 11.5 \mathrm{mg})$ and $(Z)-3$-hexenyl $O$ - $\beta$-D-glucopyranoside $(\mathbf{1 0}, 6.4 \mathrm{mg})$. Fraction $2-9$ was subjected to preparative HPLC-ODS with solvent system VIII to give $(6 R, 9 S)$-3-oxo-aionol 9- $O-\beta$-D-glucopyranoside $(4,17.3 \mathrm{mg})$. Fraction $3(1.2 \mathrm{~g})$ was subjected to a column of RP-18 using solvent system V, affording seven fractions. Fraction 3-5 was purified by preparative HPLC-ODS with solvent system VII to provide debiloside $\mathrm{B}(\mathbf{5}, 2.5 \mathrm{mg})$, and $(7 S, 8 R)$-dehydrodiconiferyl 4- $O$ - $\beta$-D-glucopyranoside $(11,6.0 \mathrm{mg})$. Fraction $5(1.4 \mathrm{~g})$ was separated on a column of RP-18 using solvent system $\mathrm{V}$ to give six fractions. Fraction 5-1 was further purified by preparative HPLC-ODS with solvent system VI to provide a new compound, $(3 S, 5 R, 6 S, 7 E, 9 S)$-megastigman-7-ene-5,6-epoxy3,9-diol 3,9-O- $\beta$-D-diglucopyranoside (3, $11.4 \mathrm{mg})$. Kaempferol 3-Osophoroside $(6,78.6 \mathrm{mg})$ was obtained from fraction 5-4 by crystallization. Fraction $6(670.0 \mathrm{mg})$ was similarly separated on a column of RP-18 using solvent system $\mathrm{V}$ to afford six fractions, giving L-tryptophan $(\mathbf{1 2}, 22.1 \mathrm{mg})$, and kaempferol 3,7-O- $\beta$-D-diglucopyranoside $(7,14.6 \mathrm{mg})$ by crystallization from fractions 6-1 and 6-3, respectively. Finally, fraction 8 (1.36g) was subjected to a column of RP-18 using solvent system $\mathrm{V}$ to provide kaempferol 3 - $O$-sophoroside-7- $O$ - $\beta$-D-glucopyranoside $(\mathbf{8}, 59.4 \mathrm{mg})$ by crystallization from fraction $8-2$

The aerial portion of the second species, E. diffusum $(595.0 \mathrm{~g})$, was similarly extracted with $\mathrm{MeOH}$, and concentrated to dryness. This part was suspended in $\mathrm{H}_{2} \mathrm{O}$ and partitioned with $\mathrm{Et}_{2} \mathrm{O}$. The water layer was applied to a column of Diaion HP-20 and eluted with $\mathrm{H}_{2} \mathrm{O}, \mathrm{MeOH}$, and $\mathrm{Me}_{2} \mathrm{CO}$, successively. The portion eluted with methanol $(1.5 \mathrm{~g})$ was repeatedly chromatographed on a column of silica gel using solvent systems I $(500 \mathrm{ml})$, II $(500 \mathrm{ml})$, III $(500 \mathrm{ml})$ and IV $(500 \mathrm{ml})$, respectively, to provide four fractions. Fraction $2(378.2 \mathrm{mg})$ was applied to a column of RP-18 using solvent system $\mathrm{V}$ to give five fractions. Fraction $2-2$ was purified by preparative HPLC-ODS with solvent system VII to yield $(3 S, 5 R, 6 S, 7 E, 9 S)$-megastigman-7-ene-5,6-epoxy-3,9-diol 3-O- $\beta$-D-glucopyranoside $(\mathbf{1 3}, 6.3 \mathrm{mg})$ and sammangaoside A $(2,1.8 \mathrm{mg})$. Fraction $3(536.0 \mathrm{mg})$ was similarly applied to a column of RP-18 using solvent system V to give L-tryptophan (12, $18.5 \mathrm{mg}$ ) and kaempferol 3-O-sophoroside $(6,23.4 \mathrm{mg})$ by crystallization from fractions 3-2 and 3-4, respectively.

$(3 S, 5 R, 6 S, 7 E, 9 S)$-Megastigman-7-ene-5,6-epoxy-3,9-diol 3,9-O- $\beta$-D-Diglucopyranoside (3): Amorphous powder, $[\alpha]_{\mathrm{D}}^{28}-75.7^{\circ}(c=0.76, \mathrm{MeOH})$ ${ }^{1} \mathrm{H}-\mathrm{NMR}\left(\mathrm{CD}_{3} \mathrm{OD}\right)$ : see Table $1 ;{ }^{13} \mathrm{C}-\mathrm{NMR}\left(\mathrm{CD}_{3} \mathrm{OD}\right)$ : see Table 2; HRAPCI-MS, $m / z$ : $585.2308[\mathrm{M}+\mathrm{Cl}]^{-}$(Calcd for $\mathrm{C}_{25} \mathrm{H}_{42} \mathrm{ClO}_{13}: 585.2292$ ).

$(3 S, 5 R, 6 S, 7 E, 9 S)$-Megastigman-7-ene-5,6-epoxy-3,9-diol 3-O- $\beta$-D-Glucopyranoside (13): Amorphous powder, $[\alpha]_{\mathrm{D}}^{28}-52.3^{\circ}(c=0.40, \mathrm{MeOH}) ;{ }^{1} \mathrm{H}-$ NMR $\left(\mathrm{CD}_{3} \mathrm{OD}\right)$ : see Table $1 ;{ }^{13} \mathrm{C}-\mathrm{NMR}\left(\mathrm{CD}_{3} \mathrm{OD}\right)$ : see Table 2; HR-APCIMS, $m / z$ : $423.1791[\mathrm{M}+\mathrm{Cl}]^{-}$(Calcd for $\mathrm{C}_{19} \mathrm{H}_{32} \mathrm{ClO}_{8}$ : 423.1783).

Enzymatic Hydrolysis of Compounds 2, 3 and 13 Each sample of 2 $(10.2 \mathrm{mg}), \mathbf{3}(10.0 \mathrm{mg})$ and $\mathbf{1 3}(6.0 \mathrm{mg})$ was hydrolyzed with crude hesperidinase $(25 \mathrm{mg})$ in $2 \mathrm{ml}$ of $\mathrm{H}_{2} \mathrm{O}$. After stirring at $37^{\circ} \mathrm{C}$ for $48 \mathrm{~h}$, the reaction mixtures were extracted with EtOAc, and then evaporated to dryness to afford (3S,5R,6S,7E,9S)-megastigman-7-ene-5,6-epoxy-3,9-diol (2a, $5.5 \mathrm{mg}$; 3a, $2.3 \mathrm{mg}$ and $13 \mathrm{a}, 3.6 \mathrm{mg}$ ). The structure was identified by ${ }^{1} \mathrm{H}-$ and ${ }^{13} \mathrm{C}-$ NMR spectral analysis and the optical rotation values. The aqueous layer of each experiment was evaporated to give the sugar fraction.

Determination of the Absolute Configuration of Glucose Standard samples of thiazolidine derivatives of D- and L-glucoses [methyl 2-(D-glucopentahydroxypentyl)-thiazolidine-4(R)-carboxylate and methyl 2-(L-glucopentahydroxypentyl)-thiazolidine-4(R)-carboxylate] were prepared according to the methods as described in the literature. ${ }^{23,24)}$ Two spots of the derivatives of D-glucose (Rf: 0.42, 0.49) appeared on TLC with the solvent system $\mathrm{CHCl}_{3}-\mathrm{MeOH}-\mathrm{H}_{2} \mathrm{O}(50: 20: 3)$ due to $\mathrm{C}-2$ epimers, while only one spot was found for the derivative of L-glucose ( $R f: 0.45)$. The sugar fraction from 2 was treated using the same methods as the standard samples. It was shown to contain methyl 2-(D-gluco-pentahydroxypentyl)-thiazolidine-4(R)-carboxylate, identified by TLC ( $R f: 0.42,0.49, \mathrm{C}-2$ epimers of thiazolidine), by comparison of the $R f$ values with those of standard samples. In the same way, the sugar fractions of $\mathbf{3}$ and $\mathbf{1 3}$ also contained methyl 2-(D-gluco-pentahydroxypentyl)-thiazolidine- $4(R)$-carboxylates $(R f: 0.42,0.49)$.

Acknowledgments This study was financially supported by Chulabhorn Research Institute, the Thailand Research Fund, and Commission of Higher Education. We also thank Mr. Noopian Hongyotee of Nam-Nao National Park and Mr. Jom Inpa of Doi-Phu-Kha National Park for help in obtaining the plant materials.

\section{References}

1) Saleh N. A. M., Abdalla M. F., Phytochemistry, 19, 987 (1980).

2) Viet M., Beckert C., Höhna C., Bauer K., Geiger H., Phytochemistry, 38, 881-891 (1995)

3) Wiedenfeld H., Cetto A. A., Amador C. P., Biochem. Syst. Ecol., 28, 395-397 (2000)

4) Wang X., Jia Z., Xibei Zhiwu Xuebao, 25, 2524-2528 (2005).

5) Xu X.-H., Ruan B.-Q., Jiang S.-H., Zhu D.-Y., Zhongguo Tianran Yaowu, 3, 93-96 (2005)

6) Xu X.-H., Tan C.-H., Jiang S.-H., Zhu D.-Y., Helv. Chim. Acta, 89, $1422-1426$ (2006)

7) Matsunami K., Takamori I., Shinzato T., Aramoto M., Kondo K., Otsuka H., Takeda Y., Chem. Pharm. Bull., 54, 1403-1407 (2006).

8) Pabst A., Barron D., Sémon E., Schreier P., Phytochemistry, 31, 1649-1652 (1992).

9) Osorio C., Duque C., Fujimoto Y., J. Agric. Food Chem., 47, 16411645 (1999).

10) Kanchanapoom T., Kasai R., Chumsri P., Hiraga Y., Yamasaki K., Phytochemistry, 58, 333-336 (2001).

11) Yu Q., Matsunami K., Otsuka H., Takeda Y., Chem. Pharm. Bull., 53, $800-807$ (2005)

12) Kasai R., Suzuo M., Asakawa J., Tanaka O., Tetrahedron Lett., 1977, $175-178$ (1977)

13) Çalis İ., Kuruüzüm-Uz. A., Lorenzetto P. A., Rüedi P., Phytochemistry, 59, $451-457$ (2002)

14) Umehara K., Hattori I., Miyase T., Ueno A., Hara S., Kageyama C., Chem. Pharm. Bull., 36, 5004-5008 (1998).

15) Mizutani K., Yuda M., Tanaka O., Saruwatari Y.-I., Fuwa T., Jia M.-R. Ling Y.-K., Pu X.-F., Chem. Pharm. Bull., 36, 2689-2690 (1988).

16) Yoshikawa M., Shimada H., Saka M., Yoshizumi S., Yamahara J., 
Matsuda H., Chem. Pharm. Bull., 45, 464- 469 (1997).

17) Yoshikawa M., Murakami T., Shimada H., Yoshizumi S., Saka M., Yamahara J., Matsuda H., Chem. Pharm. Bull., 46, 1008-1014 (1998).

18) Della M. G., Fiorentino A., Monaco P., Previtera L., Sorgente M. G., Nat. Prod. Lett., 7, 267-273 (1995).

19) Ishikawa T., Sega Y., Kitajima J., Chem. Pharm. Bull., 49, 584-588 (2001).

20) Iijima T., Yaoita Y., Kikuchi M., Natural Med., 57, 75 (2003).
21) Ling S.-K., Takashima T., Tanaka T., Fujioka T., Mihashi K., Kouno I., Fitoterapia, 75, 785-788 (2004)

22) Takeda Y., Masuda T., Morikawa H., Ayabe H., Hirata E., Shinzato T., Aramoto M., Otsuka H., Phytochemistry, 66, 727-732 (2005).

23) Hara S., Okabe H., Mihashi K., Chem. Pharm. Bull., 35, 501-506 (1987).

24) Miyaichi Y., Matsuura M., Tomimori T., Natural Med., 49, 92-94 (1995). 